\title{
Invasive Colonic Entamoebiasis in Wild Cane Toads, Australia
}

\section{Cathy M. Shilton, Jan Šlapeta, Richard Shine, Gregory P. Brown}

We detected a disease syndrome in free-ranging Australian cane toads involving atypical behavior and emaciation that is associated with a previously undescribed Entamoeba sp. that infiltrates the colonic lining, causing it to slough. The organism may become seasonally pathogenic when toads are under hydric and nutritional stress.

$\mathrm{T}$ he emergence of new diseases in wildlife substantially threatens global biodiversity in many taxa (1), but amphibians face unusually high risk for pathogen-mediated population declines $(2,3)$. Disease outbreaks among invasive amphibians are of particular concern because the invader may imperil native fauna by transmitting new pathogens (1). We documented severe (lethal) colitis of wild cane toads (Rhinella marina) in Australia associated with Entamoeba spp.

Cane toads were introduced to eastern Australia in 1935 and have now spread 2,000 km westward across the continent. The disease outbreak was observed at the University of Sydney Tropical Ecology Research Facility (TERF), in Australia's Northern Territory. The area experiences a wet-dry tropical climate, with high temperatures year-round but with rainfall limited to a 6-month wet season (November-May). Cane toads reached TERF in 2005, and the disease outbreak occurred 9 years later.

\section{The Study}

In August 2014, we noticed dead and moribund toads around the grounds of TERF. In daylight, emaciated toads were found sitting in puddles of water formed under the building's air conditioners. These diurnal observations were unprecedented; toads at this site were normally nocturnal and seen hydrating only in this manner at night. In addition, on several mornings, we observed moribund toads on open areas of lawn, fully exposed to sunlight and apparently too weak to seek refuge. During September and October 2014, we euthanized and necropsied 22 toads found hydrating or

Author affiliations: Northern Territory Department of Primary Industry and Resources, Darwin, Northern Territory, Australia (C.M. Shilton); University of Sydney, Sydney, New South Wales, Australia (J. Šlapeta, R. Shine, G.P. Brown)

DOI: https://doi.org/10.3201/eid2408.180101 otherwise diurnally active near the TERF buildings. For comparative purposes we also necropsied 2 other groups of toads: 7 collected during November 2014 from a lagoon 30 $\mathrm{km}$ from TERF and 8 collected during February 2015 from the TERF grounds (Table 1, https://wwwnc.cdc.gov/EID/ article/24/8/18-0101-T1.htm).

We detected invasive amebiasis by histologic analysis in all 3 groups, but disease was most prevalent and intense in the dry-season TERF toads (Table 1; online Technical Appendix, https://wwwnc.cdc.gov/EID/article/24/8/18-0101Techapp1.pdf). The most severe cases were detected in toads in poor body condition with overt illness (online Technical Appendix). Gross pathologic findings ranged from no obvious lesions in mildly affected toads to thickened colonic walls with hyperemic serosal vasculature and hemorrhagic content in severely affected toads (Figure 1, panel A). Histologically appreciable lesions (invasive amebiasis) were commonly limited to the colon, although in severely affected toads, lesions extended through the small intestine and, rarely, into the stomach. The intestinal mucosal epithelium was variably hyperplastic, showing moderate to marked lymphoplasmacytic infiltration, to eroded or deeply ulcerated, showing associated granulocyte and macrophage infiltration. Organisms consistent in morphology with Entamoeba spp. were among mucosal epithelial cells, often near the basement membrane and rarely within the lamina propria (Figure 1, panel B; online Technical Appendix) and not present in other organs.

We applied environmental DNA sequencing to identify the community of eukaryotes (diversity profile) within the colons of 8 infected and 10 uninfected animals based on histopathologic investigation. From the 18 colon scrapings, we obtained 1,365,109 eukaryotic V1-V3 small subunit (SSU)-rDNA high-quality Illumina MiSeq (Illumina, San Diego, CA, USA) reads clustered into operational taxonomic units (OTU). Three OTUs demonstrated perfect or high-percentage identity with SSU rDNA sequences of the amebae in the genus Entamoeba: E. ranarum (OTU_16) and 2 new cryptic species (OTU_12 and OTU_119 [Figure 2]). Using SSU-rDNA Entamoeba species-specific primers, we confirmed the presence of E. ranarum (OTU_16) and Entamoeba sp. CT1 (OTU_12) (GenBank accession nos. MG714920-MG714921). The new Entamoeba sp. CT1 (OTU_12) was significantly more abundant in toads with histologically diagnosed invasive amebiasis $(\mathrm{t}=2.2$, d.f. $=16, p=0.04$; Table 2, https://wwwnc.cdc.gov/EID/ 
Figure 1. Invasive colonic entamoebiasis in wild cane toads (Rhinella marina), tropical Australia, 2014-2015. A) Toad with severe colonic amebiasis. The colon (C) has been opened to show intraluminal hemorrhagic content and blood clots. There is segmental full-thickness necrosis of the colon wall (white arrow). Lung (L), small intestine (S), and gall bladder $(\mathrm{G})$ are annotated for perspective. B) Photomicrograph of colonic amebiasis. The affected segment of mucosal epithelium, which contains several amebae
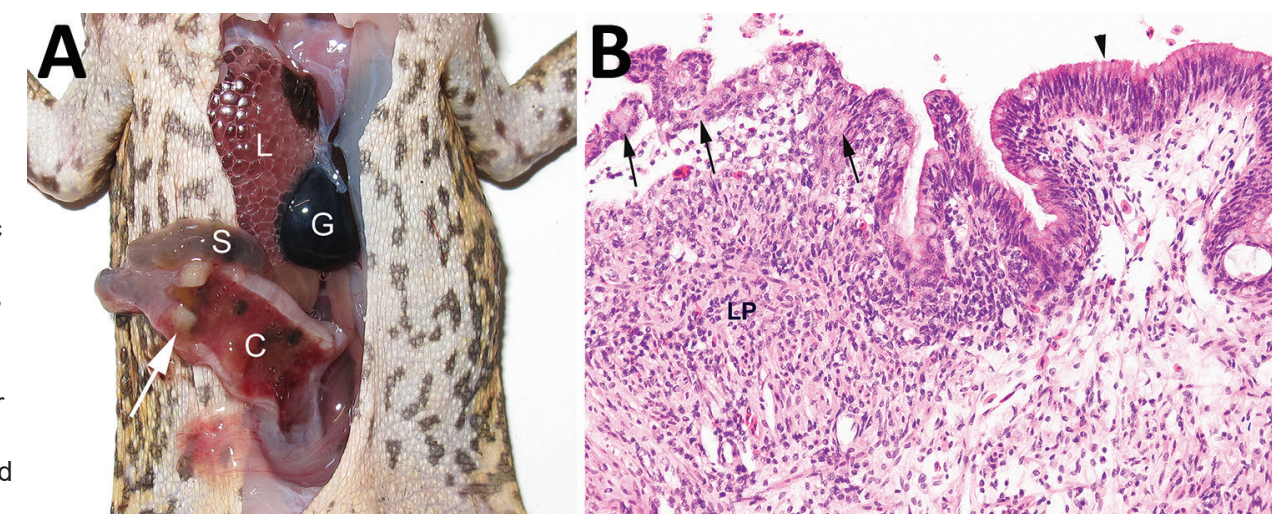
epithelium is present at right (arrowhead). There is lymphohistiocytic and granulocytic infiltration of the lamina propria underlying the affected epithelium. Hematoxylin and eosin stain. Original magnification $\times 200$.

article/24/8/18-0101-T2.htm) and significantly more abundant in toads with more severe colonic lesions $\left(\mathrm{F}_{1,16}=7.0, \mathrm{p}\right.$ $=0.017)$. OTU_12 was also detected at low levels in clinically healthy toads without histologic evidence of invasive disease from the site $30 \mathrm{~km}$ away from TERF (Table 1). Entamoeba ranarum (OTU_16) was no more prevalent or abundant in diseased toads than in healthy conspecifics, suggesting that OTU_12 (rather than E. ranarum) is the causative agent of the colitis.

Although biologists had monitored toads at the site since 2005, no unusual mortality was observed until 2014. The disease outbreak involved conspicuous behavior, severe clinical disease, and high mortality. Populations of invasive species (including Australian cane toads) often collapse after establishment, but the causes usually are unclear (4). An investigation into declines of Australian cane toad populations (5) posited an unknown microbial disease as a possible cause. Plausibly, OTU_12 could be that unknown pathogen. It might have remained undetected until now because rapid postmortem decomposition of the colon lining obscures lesions. Euthanizing toads in the final stages of the disease and immediately fixing their tissue enabled us to detect the lesions histologically.

\section{Conclusions}

To our knowledge, the only published description of pathology associated with amebic infection in amphibians is a case of renal disease in a single captive cane toad (6).
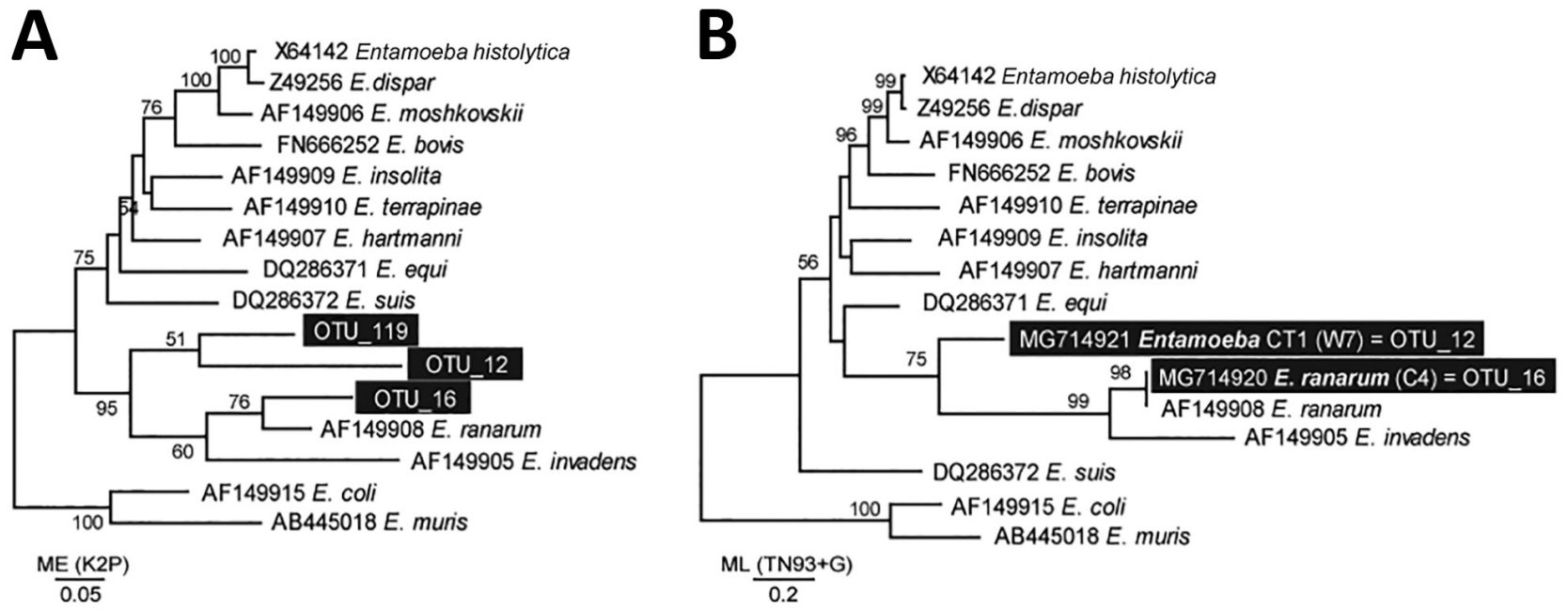

Figure 2. Phylogenetic inference of cane toad (Rhinella marina) Entamoeba SSU-rDNA sequences. Entamoeba SSU-rDNA sequences obtained using environmental next-generation amplicon sequencing $(A)$ and conventional amplification using Entamoeba-specific primers $(B)$ were aligned with available representative SSU-rDNA sequences. Each sequence is accompanied by GenBank accession number and Entamoeba species name. New sequences are in black boxes. Bootstrap support values (500 replicates) are shown next to the branches. The evolutionary distances were computed using the maximum-likelihood method and are in the units of number of base substitutions per site (scale bars). New sequences are representative of the OTU contigs (A) or are sequences directly from PCR amplicon (B). OTU, operational taxonomic unit; SSU, small subunit. 
Although a recent survey of cane toads in Puerto Rico recorded 2 animals with histologic evidence of amebic enteritis (7), extensive surveys of intestinal protozoa in Australian toads did not detect amebiasis (8). In other wild anurans, amebas (including Entamoeba spp.) sometimes are evident cytologically in the intestine (9) but have never been linked to disease.

The genus Entamoeba infects a range of taxa, often as commensals, and less commonly as pathogens $(10,11)$. In humans, E. histolytica is associated with extensive illness and death $(12,13)$. However, the presence of Entamoeba is inconsistently associated with disease and might depend on interactions between the environment, host, and parasite $(12,13)$. For example, poor nutritional status facilitates invasive amebiasis in humans (12-14). Likewise, anorexia predisposes captive herpetofauna to invasive entamoebiasis (11). Furthermore, interactions between Entamoeba spp. and other organisms in the gut microbiome may affect growth or virulence of the pathogen $(11,12)$.

Based on this pattern of Entamoeba pathogenesis in other species and on knowledge of toad ecology, we speculate the following scenario for the disease outbreak. Toads ingest encysted OTU_12 by foraging on the ground where an infected host has defecated (12). Rates of infection increase during the dry season when toads congregate nightly around dwindling water sources $(5,15)$. Dry-season congregations of toads also decrease food intake as competition for food increases (15). Decreased feeding alters the intestinal microbiome and causes Entamoeba in the colon to activate genes that enable it to feed on epithelial cells instead of colon contents. Destruction of the colon wall causes fluid imbalance, forcing toads to remain in moist areas to prevent dehydration. As destruction of the colon wall progresses, bacterial infection leads to septicemia, anorexia, and eventual death. Further experimental studies are needed to verify this conjectured chain of causation.

The circumstances underlying the unprecedented mortality event and its implications require further investigation. Of paramount importance is determining the current distribution of OTU_12, its original host, and whether native frog populations are at risk from the disease. Isolating and culturing OTU_12 for reference material and morphologic characterization of cysts and trophozoites would facilitate further study. Determining whether changes in the environment, microbiome, or both cause Entamoeba to switch from commensal to pathogenic and the role the disease may play in controlling populations of cane toads also warrant further study.

\section{Acknowledgments}

We thank 2 anonymous reviewers for helpful comments.

The Australian Research Council provided funding for this study.

\section{About the Author}

Dr. Shilton is a veterinary pathologist at the Northern Territory Department of Primary Industry and Resources. Her primary research interest is wildlife pathology.

\section{References}

1. Crowl TA, Crist TO, Parmenter RR, Belovsky G, Lugo AE. The spread of invasive species and infectious disease as drivers of ecosystem change. Front Ecol Environ. 2008;6:238-46. http://dx.doi.org/10.1890/070151

2. Stuart SN, Chanson JS, Cox NA, Young BE, Rodrigues ASL, Fischman DL, et al. Status and trends of amphibian declines and extinctions worldwide. Science. 2004;306:1783-6. http://dx.doi.org/10.1126/science. 1103538

3. Daszak P, Cunningham AA, Hyatt AD. Infectious disease and amphibian population declines. Divers Distrib. 2003;9:141-50. http://dx.doi.org/10.1046/j.1472-4642.2003.00016.x

4. Simberloff D, Gibbons L. Now you see them, now you don't! Population crashes of established introduced species. Biol Invasions. 2004;6:161-72. http://dx.doi.org/10.1023/ B:BINV.0000022133.49752.46

5. Freeland WJ, Delvinqueir BLJ, Bonnin B. Food and parasitism of the cane toad, Bufo marinus, in relation to time since colonization. Aust Wildl Res. 1986;13:489-99. http://dx.doi.org/10.1071/WR9860489

6. Valentine BA, Stoskopf MK. Amebiasis in a neotropical toad. J Am Vet Med Assoc. 1984;185:1418-9.

7. Burrowes PA, Joglar RL, Green DE. Potential causes for amphibian declines in Puerto Rico. Herpetologica. 2004;60:14154. http://dx.doi.org/10.1655/03-50

8. Delvinquier BLJ, Freeland WJ. Protozoan parasites of the cane toad, Bufo marinus, in Australia. Aust J Zool. 1988;36:301-16. http://dx.doi.org/10.1071/ZO9880301

9. Kudo R. On the protozoa parasitic in frogs. Trans Am Microsc Soc. 1922;41:59-76. http://dx.doi.org/10.2307/3221896

10. Silberman JD, Clark CG, Diamond LS, Sogin ML. Phylogeny of the genera Entamoeba and Endolimax as deduced from smallsubunit ribosomal RNA sequences. Mol Biol Evol. 1999;16:174051.http://dx.doi.org/10.1093/oxfordjournals.molbev.a026086

11. Ratcliffe HL, Geiman QM. Spontaneous and experimental amebic infection in reptiles. Arch Pathol (Chic). 1938;25:160-84.

12. Faust DM, Guillen N. Virulence and virulence factors in Entamoeba histolytica, the agent of human amoebiasis. Microbes Infect. 2012;14:1428-41.http://dx.doi.org/10.1016/ j.micinf.2012.05.013

13. Salles JM, Salles MJ, Moraes LA, Silva MC. Invasive amebiasis: an update on diagnosis and management. Expert Rev Anti Infect Ther. 2007;5:893-901.http://dx.doi.org/ 10.1586/14787210.5.5.893

14. Thibeaux R, Weber C, Hon C-C, Dillies M-A, Avé P, Coppée J-Y, et al. Identification of the virulence landscape essential for Entamoeba histolytica invasion of the human colon. PLoS Pathog. 2013;9:e1003824.http://dx.doi.org/10.1371/ journal.ppat.1003824

15. Brown GP, Kelehear C, Shine R. Effects of seasonal aridity on the ecology and behaviour of invasive cane toads in the Australian wet-dry tropics. Funct Ecol. 2011;25:1339-47. http://dx.doi.org/10.1111/j.1365-2435.2011.01888.x

Address for correspondence: Gregory P. Brown, University of Sydney, School of Life and Environmental Science, Heydon-Laurence Bldg, A08, Sydney, NSW 2006, Australia; email: gregory.brown@sydney.edu.au 